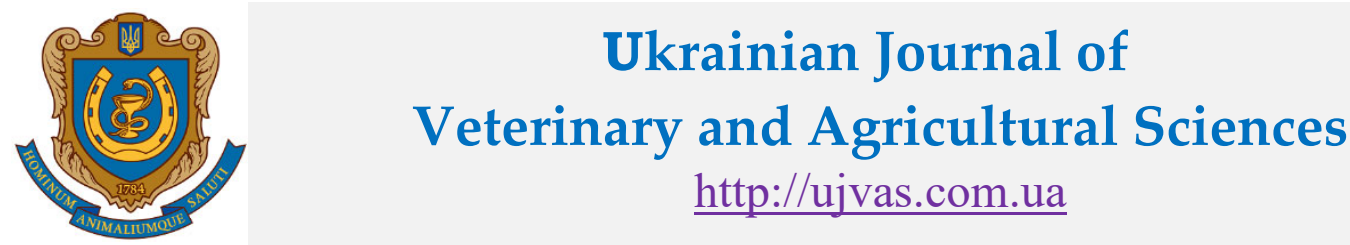

Stepan Gzhytskyi National University of Veterinary Medicine and Biotechnologies Lviv

\begin{tabular}{l|l|l} 
original article & UDC 619:579.852.11:616-08 & doi: 10.32718/ujvas4-3.08
\end{tabular}

\title{
Antagonistic effect of Bacillus subtilis isolated and identified from different honey species against Klebsiella pneumoniae bee pathogens
}

\author{
A. R. Lakhman, O. Ye. Galatiuk, T. A. Romanishina, V. L. Behas \\ Polissia National University, Stary Boulevard, 7, Zhytomyr, 10008, Ukraine
}

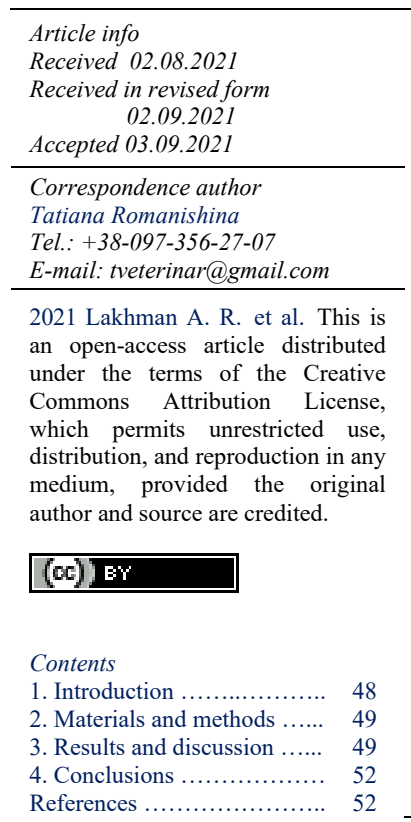

\begin{abstract}
The search for alternative methods for treating and preventing bee dysbacteriosis is a priority for beekeeping as a branch of veterinary medicine. Lime honey, buckwheat honey, flower honey, forest honey, and acacia honey were tested to evaluate their antagonistic effect against a test culture of enterobacteria of bees of Klebsiella pneumoniae species. The study was conducted in several stages: 1. Determine the activity of honey microflora against a pure culture of enterobacteria of bees of Klebsiella pneumoniae bee pathogens; 2 . The identification and isolation of Bacillus subtilis - bacteria-antagonists against Klebsiella pneumoniae bee pathogens; 3. Determine the antagonistic effect of pure culture of Bacillus subtilis against a pure culture of enterobacteria of Klebsiella pneumoniae bee pathogens. The antagonistic action of honey microorganisms and the determination of the most effective honey species were established by the diffusion method in agar wells. Staining of typical colonies from different types of honey revealed bacillary colonies of Gram-positive bacilli with endospores. Isolation of clean culture was conducted by a method of Gold. The cultural, tinctorial, and morphological signs of bacteria have been consistently determined in all investigated kinds of honey and coincided with characteristics of the Bacellaceae family. Specific belonging of bacteria-competitors was identified by biochemical typing. After determining their physiological properties in reactions and tests (activity of catalase, oxidase, urease, the ability to grow at different temperatures and to ferment carbohydrate substrate), the distinguished stamms of microorganisms from the investigated kinds of honey belong to the type of Bacillus subtilis. The repeated estimation of antagonistic action of pure cultures of Bacillus subtilis (isolated from each type of honey) against a pure culture of enterobacteria of bees of Klebsiella pneumoniae species confirmed their high activity. This type of microorganisms can represent the alternative component in probiotics at the therapy of dysbiosis of bees.
\end{abstract}

Keywords: bees, honey, identification, Bacillus subtilis, antagonism; Klebsiella pneumoniae.

\section{Citation:}

Lakhman, A. R., Galatiuk, O. Ye., Romanishina, T. A., \& Behas, V. L. (2021). Antagonistic effect of Bacillus subtilis isolated and identified from different honey species against Klebsiella pneumoniae bee pathogens. Ukrainian Journal of Veterinary and Agricultural Sciences, 4(3), $48-53$.

\section{Introduction}

The result of the intensification of the agricultural sector on a global scale changes the species structure of environmental biogeocenosis and leads to the mass mortality of bee colonies. In recent years, a high level of honey insects losses has been registered not only because of the negative impact of anthropogenic factors but also because of the toxic effects of pathogenic microflora on the microorganism Apic mellifera (Amiri et al., 2020; Galatiuk et al., 2020; Galatiuk et al., 2020). Dysbacteriosis (dysbiosis) in mammals and insects is provoked by opportunistic pathogens, the virulence of which, under favorable exogenous and endogenous conditions, is actively increasing (DeGruttola et al., 2016; Malek et al., 2019). Therefore, an urgent issue in veterinary medicine is searching for drugs alternative to antimicrobials. The creation of biological products based on living, sporeforming bacterial microorganisms is a promising area in veterinary and human medicine (Paytuví-Gallart et al., 2020;
Rodrigues et al., 2020). Probiotics, which are based on such bacteria, have an active antagonistic effect on virulentaggressive microflora, provoking disorders of the gastrointestinal tract of living organisms.

Moreover, the competitive growth of spore-forming microbes against some pathogenic enterobacteria does not affect the growth of Lacto-and bifidobacteria effective for the microorganism. Detection of Bacillus species from different kinds of honey confirms this product's medicinal and economic value (Jeon et al., 2018; Zulkhairi Amin et al., 2020). It is known that different strains of bacteria of the Bacillus subtilis species are supplemented as a probiotic additive to the diet of humans and animals (Jeon et al., 2018; Zhou et al., 2019). Moreover, the resistance to this bacterium rarely occurs in a living organism, as Bacillus subtilis synthesizes metabolites related to compounds synthesized by the microorganism (e.g., lysozyme, lectin, histamine, defensin, etc.) (Irkitova et al., 2018). Secondary metabolites of this Bacillus: enzymes, iturin, surfactin, bioinsecticides 
are well-known antimicrobial compounds (Stein, 2005; Zulkhairi Amin et al., 2020; Witazora et al., 2021). The mechanism of antimicrobial action of Bacillus subtilis is based on provoking the formation of membrane pores of bacterial cells, which subsequently leads to their lysis and apoptosis (Kumar et al., 2012; Moore et al., 2013; Vignesh et al., 2016). In contrast to Bacillus subtilis, the traditional effect of antibiotics aims to vector disruption of bacterial metabolic enzymes, which causes them to "get used" to such drugs (Wang et al., 2010; Sumi et al., 2015). Therefore, the isolation and identification of pure cultures of new strains of Bacillus subtilis have antagonistic activity against the pathogenic pathogen klebsiellosis (dysbiosis) of bees of the species Klebsiella pneumoniae, can provide an effective, organic treatment. Besides, determining the type of honey with the best antagonistic effect on the test culture of enterobacteria is a prospect for further use of honey as a source for accumulating and identifying competing bacteria.

The purpose of the study was to isolate and identify antagonist-bacteria from different kinds of honey (lime honey, buckwheat honey, flower honey, forest honey, and acacia honey) against the pure culture of enterobacteria of bees of Klebsiella pneumoniae species; identify the honey with the highest antagonistic activity against the pure culture of enterobacteria of bees of Klebsiella pneumoniae species.

\section{Materials and methods}

1. Determine the activity of honey microflora against the pure culture of enterobacteria of bees of Klebsiella pneumoniae bee pathogens

To determine the activity of honey microflora against the pure culture of enterobacteria of bees of Klebsiella pneumoniae species (test culture isolated and identified in 2019 from sick bee colonies) (Galatiuk et al., 2020), raw honey $\left(30 \mathrm{~cm}^{3}\right)$ from beehives of Ukrainian steppe breeds of the North-Western region of Ukraine was used. Samples of 5 types of honey (lime, buckwheat, flower, forest, acacia) were diluted in equal parts with distilled water $\left(45-50{ }^{\circ} \mathrm{C}\right)-$ $50 \%$ honey solutions. Experimental $50 \%$ honey solutions were prepared in the Department of Microbiology, Pharmacology, and Epizootology laboratory at Veterinary Medicine Faculty. The bacterial suspension of Klebsiella pneumonia $\left(1 \mathrm{~cm}^{3}\right)$ was obtained by washing with sterile $\mathrm{NaCl}$ solution $(0.9 \%)$ daily culture of beveled nutrient agar. The concentration of bacterial cells was adjusted according to the McFarland Turbidity Standard (Benkova et al., 2020) - 1 (approximately 3 International Turbidity Units or $3 \times 10^{8}$ colony-forming units in $\left.1 \mathrm{~cm}^{3}\right)$. Inoculation was performed deep on MPA medium (meat-peptone agar) at the rate of $1 \mathrm{~cm}^{3}$ of bacterial inoculum per $15 \mathrm{~cm}^{3}$ of nutrient agar in one Petri dish. After solidification of the mixture of agar with microorganisms (without cultivation), the antagonistic effect was determined by the agar well diffusion method (the holes of 6-8 $\mathrm{mm}$ diameter were cut with the sterile scalpel and the investigated solutions of honey solutions of $0,3 \mathrm{~cm}^{3}$, were instilled in them). The Petri dishes were kept at $21-24{ }^{\circ} \mathrm{C}$ for 2 hours to diffuse the $50 \%$ honey solutions into the agar thickness. Cultivation of cultures lasted 72 hours at a temperature of $37^{\circ} \mathrm{C}$. The experiment was performed in 5 replicates for each type of honey.

2. The identification and isolation of Bacillus subtilis - bacteria-antagonists against Klebsiella pneumoniae bee pathogens

The antagonist-bacterial family against the bee pathogen Klebsiella pneumoniae was determined by culture-tinctorialmorphological characteristics;

The genus and species of cultures were determined by biochemical typing reactions and the physiciansbacteriologists State Institution "Zhytomyr Regional Laboratory Center of the Ministry of Health of Ukraine."

3. Antagonistic effect of pure culture of Bacillus subtilis against the pure culture of enterobacteria of Klebsiella pneumoniae bee pathogens

After preparing bacterial suspensions of Bacillus subtilis (isolated from each type of honey) and Klebsiella pneumoniae, bacterial cell concentrations of Bacillus subtilis and Klebsiella pneumoniae were determined according to the McFarland turbidity standard (Benkova et al., 2020). Inoculation of Klebsiella pneumoniae was performed by deep method on MPA medium. After solidifying this medium, the agar well diffusion method (holes $6-8 \mathrm{~mm}$ in diameter were cut with a sterile scalpel, and $0.3 \mathrm{~cm}^{3}$ prepared bacterial suspensions of Bacillus subtilis isolated from each type of honey were injected into them). The cultivation lasted 72 hours at $37{ }^{\circ} \mathrm{C}$. The experiment was performed in 5 replicates.

The Animal Research Committee of the Polissia National University approved our study.

\section{Results and discussion}

\section{Results}

The antagonistic activity of honey microorganisms against the test culture of Klebsiella pneumoniae bees was characterized by competitive growth of large surface shiny white colonies with rhizoid edges (Figure $1-\mathrm{A}$ ) around the wells with a diameter of 12 to $47 \mathrm{~mm}$ (Figure 2).

A comparative analysis of the antagonistic activity of different species of kinds of honey showed that only 2 of them had zones of suppressive growth (against pure cultures of enterobacteria of Klebsiella pneumoniae bee pathogens) greater than $30 \mathrm{~mm}$ (forest and acacia kinds of honey). Furthermore, the microbial growth of buckwheat and linden kinds of honey differed from that of acacia honey by $73.09 \%$ and $68.18 \%$, respectively (Figure 2 ).

The results of culture-tinctorial-morphological characteristics of microorganisms from all studied $50 \%$ honey solutions corresponded to the characteristics of the family of bacilli (Bacillaceae) (Markey et al., 2020). At painting microorganisms from bacillary colonies by Gramm method, Gram-positive rods with endospores (Figure $1-\mathrm{C}$ ), placed sporadically and in chains (Figure $1-\mathrm{B}$ ) were determined on the background of gram-negative rods of Klebsiella pneumoniae test culture. The stroke method used the stroke method to isolate pure culture by surface seeding on MRS medium (agar de Man, Rogossa, and Sharpe) (Figure 3 - A, B). 


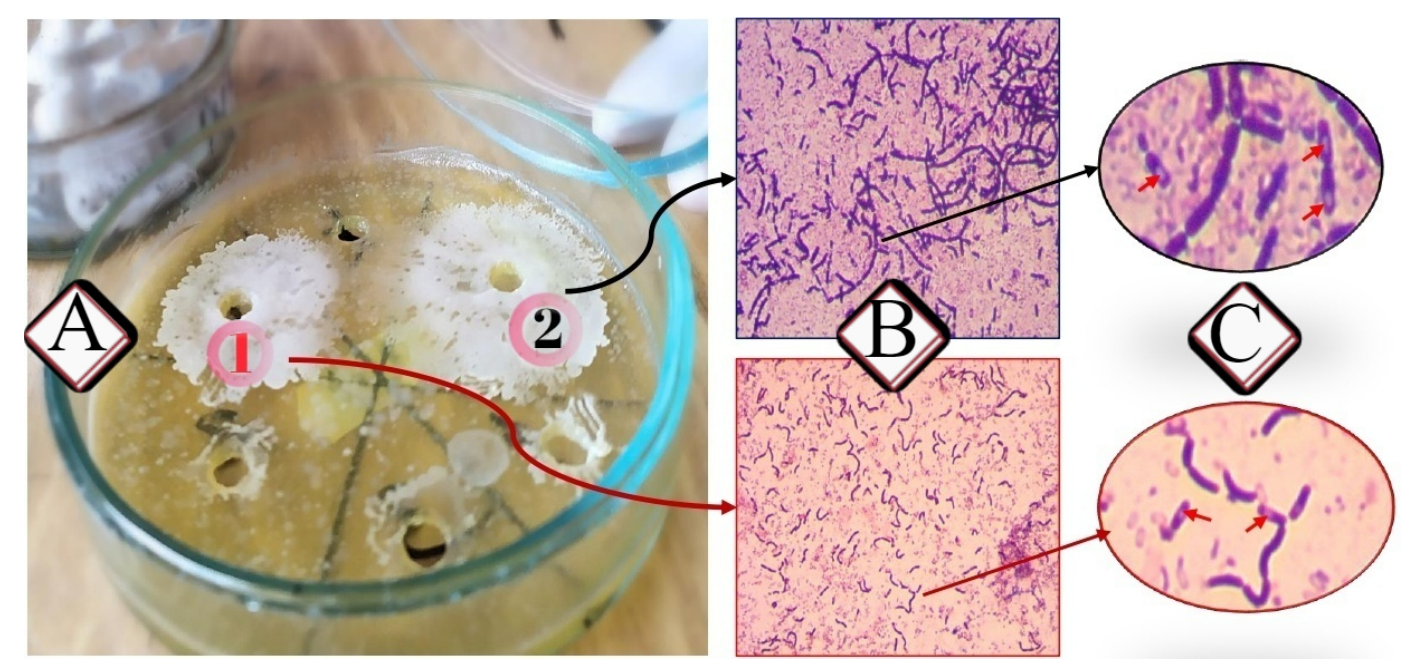

Fig. 1. Manifestation of antagonism of the studied kinds of honey against the test culture of enterobacteria of bees of Klebsiella pneumoniae species. (A) cultural characteristics of bacteria - antagonists determined by agar well diffusion method (1. forest honey; 2. acacia honey), (B) microscopic view of bacteria - antagonists under microscopy (Gram method) x 1000, (C) endospores of bacteria - antagonists of the studied kinds of honey x 10000

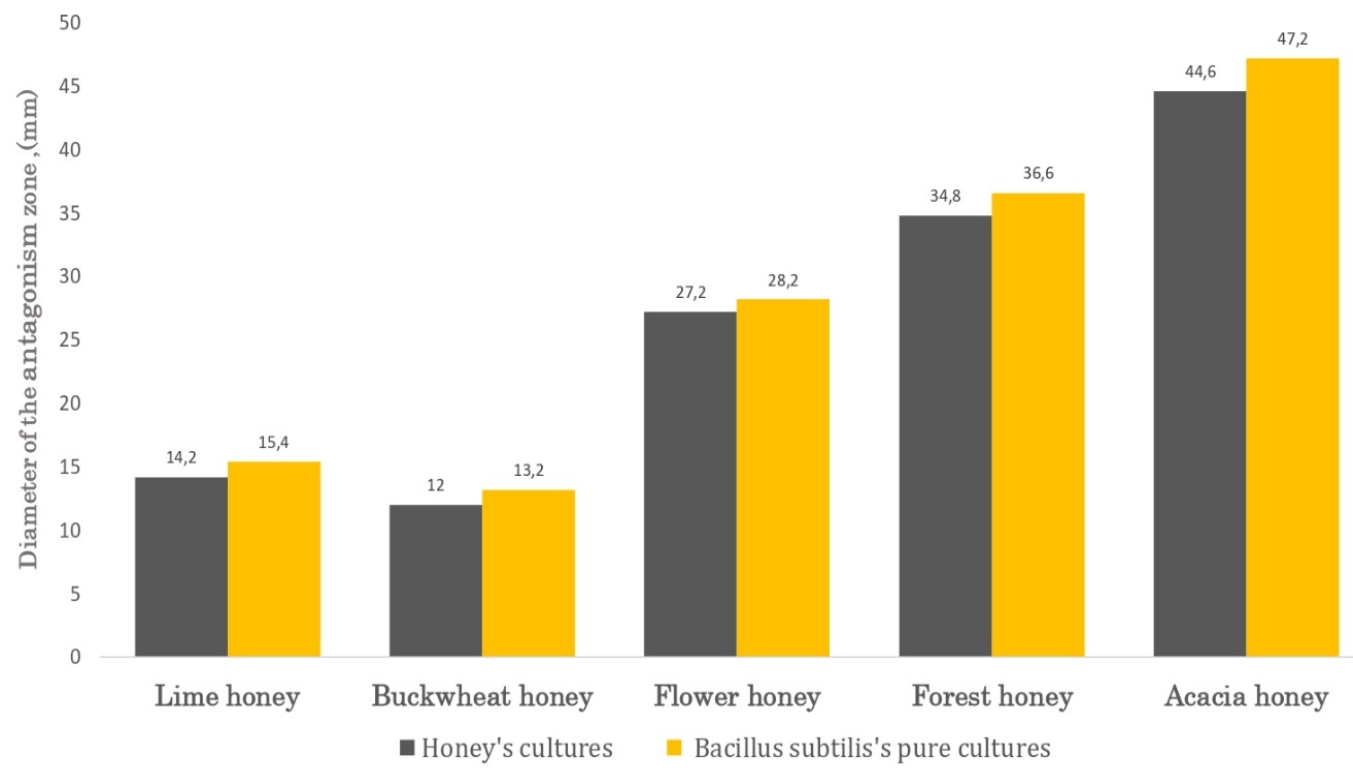

Fig. 2. Antagonistic effect of honey microflora and pure culture of Bacillus subtilis against the pure culture of enterobacteria of bees of Klebsiella pneumoniae species

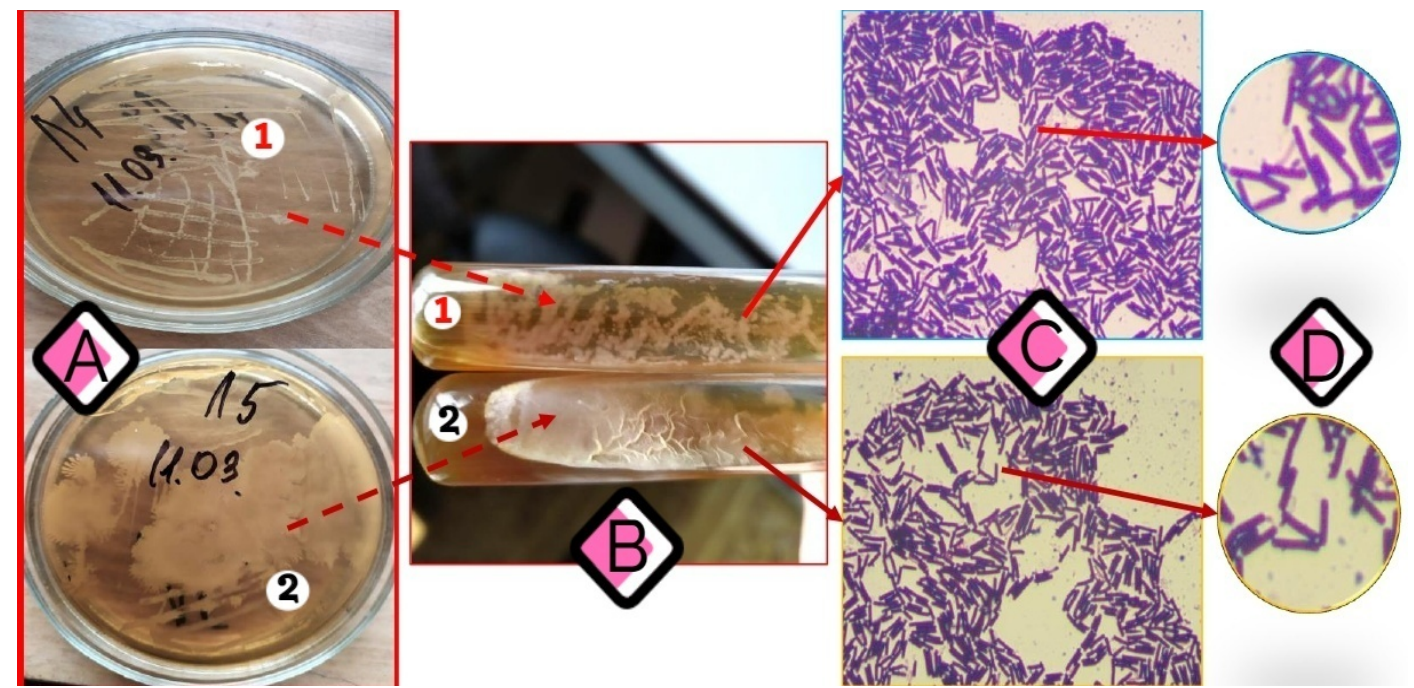

Fig. 3. Growth of pure isolates of Bacillus subtilis on MRS medium (de Man, Rogossa and Sharpe). (A) 24-hour cultures of Bacillus subtilis in Petri dishes (1. isolates of forest honey; 2. isolates of acacia honey), (B) growth of Bacillus subtilis isolates on oblique MRS agar, (C) view of pure cultures of antagonist bacteria under microscopy (Gram method) x 1000, (D) view of pure cultures of antagonist bacteria under microscopy (Gram method) x 10000 
Morphological features of the studied isolates were similar to the results of microscopy of microorganisms from bacillary colonies of honey (Figure $3-\mathrm{C}, \mathrm{D}$ ). The motility of microorganisms was detected microscopically in the drug "hanging drop" (Benkova et al., 2020) and in the formation of creeping colonies on the walls of the test tube when sown in meat-peptone gelatin (Figure $4-B$ ).

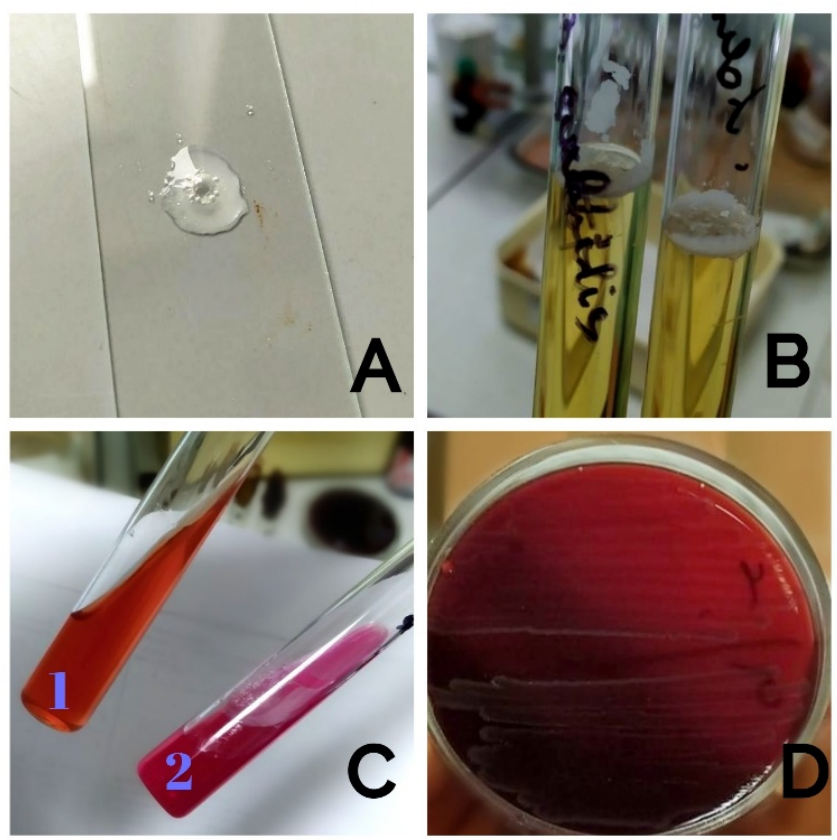

Fig. 4. Study of physiological properties and mobility of the isolated isolate of Bacillus subtilis. (A) catalase test, (B) mobility test, $(\mathrm{C})$ discoloration of the carbohydrate substrate during fermentation of monosaccharides (1. control tube; 2. experimental tube), (D) no hemolysis during growth on blood agar

When tested for oxidase, the disk of the test system did not change color, indicating the absence of this enzyme in bacteria - oxidase negative. Thus, the studied microorganisms cannot synthesize cytochrome oxidase or indophenoloxidase, so they are obligate aerobes (Benkova et al., 2020). The oxidative properties of the studied bacillary cultures considering the possibility of decomposition of hydrogen peroxide to water and molecular oxygen were detected in the reaction to catalase (Figure 4-A) - catalase positive. Identified from honey bacteria - antagonists to the test culture of Klebsiella pneumoniae belong to the genus Bacillus. The species affiliation of the competitive culture was determined in State Institution "Regional Laboratory Center of the Ministry of Health" by biochemical typing. Differentiation of antagonistic culture was performed by setting specific tests distinctive to different types of sporeforming aerobes (World Health Organization, 2003; Zasada, 2020). The ability of pure cultures to grow aggressively at $\mathrm{t}+28-+30{ }^{\circ} \mathrm{C}$ and at the same time at $\mathrm{t}+50{ }^{\circ} \mathrm{C}$; turbidity of the broth with gradual enlightenment, with the formation of a dense film, without the formation of a brittle precipitate, differentiates the studied cultures from Bacillus cereus. The absence of hemolysis zones during growth on the sheep erythrocytes medium characterizes the studied microorganisms as saprophytic bacilli (Figure $4-D$ ). Sensitivity to penicillin was not detected - during incubation of cultures with the addition of different concentrations of penicillin, the shape of bacterial cells did not change, which excludes the belonging of the antagonist culture to the species Bacillus anthracis. The culture is active in the cleavage of the carbohydrate substrate's monosaccharides (xylose, arabinose) (Figure $4-\mathrm{C}$ ). These simple sugars are a carbon source, followed by the synthesis of exogenous organic acids, capable of changing the acidosis-hydrogen index and the color of the indicator medium to crimson (Figure $4-\mathrm{C}$ (1-2)) respectively. During the urease test, the color of the medium remained yellow, i.e., the $\mathrm{pH}$ did not change, alkaline products (ammonia formed from urea) were absent. The positive reaction of Fogest-Proskauer indicates the ability of bacteria isolated from $50 \%$ honey solutions to form acetoin by adding up to $2.5 \mathrm{~cm}^{3}$ of daily culture of bacteria (from Clark's medium), $1 \mathrm{~cm}^{3}$ of alcoholic solution of $\alpha$-naphthol, and $0.4 \mathrm{~cm}^{3}$ of $40 \% \mathrm{KOH}$ (Benkova et al., 2020). Isolated strains of microorganisms from the studied honey sieves antagonists of enterobacteria of bees of Klebsiella pneumoniae species - belong to the family of the Bacillaceae, genus Bacillus, species Bacillus subtilis.

All isolated Bacillus subtilis strains showed antagonistic activity when co-cultured with Klebsiella pneumoniae, with different growth diameters (Figure 2). Compared to the data from the honey microflora activity experiment against the pure culture of Klebsiella pneumoniae, the inhibitory effect of pure Bacillus subtilis cultures was more substantial. The difference between the diameters antagonism effect of honey microflora and pure culture of Bacillus subtilis: 7,79\% (lime honey); $9.09 \%$ (buckwheat honey); $3.55 \%$ (flower honey); $4.92 \%$ (forest honey); $5.51 \%$ (acacia honey). The most effective isolates against Klebsiella pneumoniae were isolated from acacia and forest honey (Figure 2).

\section{Discussion}

We describe the isolation and identification of Bacillus subtilis bacteria isolated from different honey species and their antagonistic effect on Klebsiella pneumoniae. This type of enterobacteria causes damage to the intestinal enterocytes of bees (Rozhenkov et al., 2017), alveoli of the lungs, nephrons, and tubules of the kidneys of animals and humans (Vachvanichsanong et al., 2021). Frequent and long-term use of antibiotic therapy has led to significant resistance of these microorganisms, characterized by the presence of genes that encode the ability to synthesize carbapenemases (Polischouk et al., 2017; Bozhkova et al., 2020; Nevezhina, 2021). The genetic sequences encoding these bacterial enzymes constitute unique "mobile genetic structures" that promote the rapid spread of infections in farms, hospitals, clinics (Rusaleyev et al., 2019), and apiaries (Galatiuk et al., 2020). Regulation of the imbalance of the interaction of the components of the intestinal microbiota of the bee is a specific, modulating effect of alternative antimicrobial agents. Such an inhibitory effect was found in saprophytic sporeforming microorganisms of Bacillus subtilis species (Zulkhairi Amin et al., 2017; Irkitova et al., 2018). The primary habitat of this microorganism is the soil, rhizome, and pollen of flowering plants (Rusaleyev et al., 2019). The affinity of antimicrobial protein, synthesized by the mammalian macroorganisms and the bacillus metabolites, gives preference to Bacillus subtilis as a probiotic agent (Mnif et al., 2015; Sumi et al., 2015). Moreover, bacillary bacteria are a source of deficicidin, polymyxin, subtilin, which disrupt protein synthesis of gram-positive and gram-negative microorganisms (Kumar et al., 2012; Moore et al., 2013). A group of scientists confirmed the antagonistic activity of 
Bacillus subtilis against enterobacteria of some species (E. coli, Pseudomonas aeruginosae, Salmonella spp., Citrobacter freundii, Shigella flexneriIIa) in vitro (Irkitova et al., 2018). Physiological properties of bacteria and evaluation of the activity of their isolates are based on the final products of several biochemical transformations. The peculiarity of the modified identification of Bacillus subtilis was the use of non-specific for bacillus tests (catalase, oxidase, urea) and the nature of growth on nutrient media for various purposes (cleavage of carbohydrate substrate using arabinose and xylose as the only carbon source, undergoes three stages of transformation: from ribulose in the first stage to ribulose-5-phosphate - in the second stage and with the help of ribulose-5-phosphate-4-epimerase to xylulose-5phosphate in the third stage (Zahoor et al., 2012), the use of indicator systems paper for the identification of microorganisms № 2 - Fogest-Proskauer reaction, determination of hemolysis of sheep erythrocytes; the growth under aerobic conditions on meat-and-peptone agar and broth. This method is economical, fast, precise, and reliable. We found out that the competitive growth of Bacillus subtilis over the test culture of Klebsiella pneumoniae in vitro by diffusion method in agar wells (Irkitova et al., 2018), with the highest level of antagonism between acacia and forest kinds of honey, is of scientific and practical importance. The Bacillus subtilis strains are contained in a consortium with other honey microorganisms; there is a mutual inhibition phenomenon, which probably ceases when pure cultures are isolated (Olaitan et al., 2007; Silva et al., 2017). The manifestation of antagonism with a $50 \%$ honey solution of acacia honey is due to the density and the possibility of its diffusion into agar with a pure culture of enterobacteria. The effect of a $50 \%$ honey solution of forest honey is interpreted by the variety of Phyto-ingredients of honey plants - the composition of honey. Since, during honey collection, the outer surfaces of the proboscis of bees come into contact with pollen bacteria (including strains of Bacillus subtilis), the bee serves as a mobile vector of getting "beneficial" bacteria from a large number of plants in honey.

\section{Conclusions}

Biochemical typing is one of the alternative methods of identifying Bacillus subtilis bacterial species, which combines the results of enzymatic transformations in vitro with the physiological properties of bacteria and interpret the mechanisms of action of Bacillus subtilis in drugs acting on insects in the treatment and prevention of bee dysbiosis.

The diffusion method in agar wells is adequate for recording the results of the interaction of antagonist microorganisms (Bacillus subtilis) with the studied test cultures and allows to record their cultural characteristics in vitro.

The bacteria Bacillus subtilis isolated from acacia and forest honey has significant antagonistic properties against the pure culture of enterobacteria of Klebsiella pneumoniae bee pathogens.

\section{Acknowledgment}

Gratitude for participation in general biochemical typing and determining the species identity of Bacillus subtilis, O. M. Lysenko, V. V. Shimanska, bacteriologists of the laboratory of hazardous infections.

\section{Conflict of interest}

There is no conflict of interest.

\section{Financial Disclosure}

This study has received no financial support.

\section{References}

Amiri, E., Strand, M. K., Tarpy, D. R., \& Rueppell O. (2020). Honey bee queens and virus infections. Viruses, 12(3), 322. DOI: $10.3390 / \mathrm{v} 12030322$.

Benkova, M., Soukup, O., \& Marek, J. (2020). Antimicrobial susceptibility testing: currently used methods and devices and the near future in clinical practice. Journal of applied microbiology, 129(4), 806-822. DOI: 10.1111/jam.14704.

Bozhkova, S. A., Gordina, E. M., Schneider, O. V., Rukina, A. N., \& Shabanova, V. V., (2020). Resistance of carbapenemase-producing Klebsiella pneumoniae isolated from patients with orthopedic infection. Clinical Microbiology and Antimicrobial Chemotherapy, 122(47), 47-52. DOI: 10.36488/cmac.2020.1.47-52.

DeGruttola, A. K., Low, D., Mizoguchi, A., \& Mizoguchi, E. (2016). Current understanding of dysbiosis in disease in human and animal models. Inf. Bowel. dis, 22(5), 1137-1150. DOI: $10.1097 / \mathrm{mib} .0000000000000750$.

Galatiuk, O. Ye., Romanishina, T. A., Lakhman, A R., Behas, V. L., Andriichuk, A. M., \& Solodka, L. O. (2020). Application of biochemical typing in veterinary medicine in bee enterobacterioses to determine Klebsiella Pneumoniae. Scientific Messenger of LNU of Veterinary Medicine and Biotechnologies. Series: Veterinary Sciences, 22(99), 101-106. DOI: 10.32718/nvlvet9916.

Galatiuk, O., Romanishina, T., Lakhman, A., Zastulka, O., \& Balkanska, R. (2020). Isolation and identification of Klebsiella aerogenes from bee colonies in bee dysbiosis. The Thai $J$ of Vet Med, 50(3), 353-361. URL: https://he01.tcithaijo.org/index.php/tjvm/article/view/245844.

Irkitova, A. N., Grebenshchikova, A. V., \& Matsyura, A. V. (2018). Antagonistic activity of Bacillus subtilis strains isolated from various sources. Ukrainian Journal of Ecology, 8(2), 354-364. DOI: 10.15421/2018 354.

Jeon, H. L., Yang, S. J., Son, S. H., Kim, W. S., Lee, N. K., \& Paik, H. D. (2018). Evaluation of probiotic Bacillus subtilis P229 isolated from cheonggukjang and its application in soybean fermentation. LWT, 97, 94-99. DOI: 10.1016/j.lwt.2018.06.054.

Kumar, P., Dubey, R. C., \& Maheshwari, D. K. (2012). Bacillus strains isolated from rhizosphere showed plant growth promoting and antagonistic activity against phytopathogens. Microbiological Research, 167(8), 493-499. DOI: 10.1016/j.micres.2012.05.002.

Malek, A., McGlynn, K., Taffner, S., Fine, L., Tesini, B., Wang, J., Mostafa, H., Petry, Sh., Perkins, A., Graman, P., Hardy, D., \& Pecora, N. (2019). Next-generation-sequencing-based hospital outbreak investigation yields insight into Klebsiella aerogenes population structure and determinants of carbapenem resistance and pathogenicity. Antimicrobial agents and chemotherapy, 63(6). DOI: 10.1128/AAC.02577-18.

Manual for Laboratory Diagnosis of Anthrax. (2003). World Health Organization. New Delhi: Regional Office for SouthEast Asia, 58. DOI: 10.3390/microorganisms8010125.

Markey, B., Leonard, F., Archambault, M., Cullinane, A., \& Maguire, D. (2013). Clinical veterinary microbiology e-book. Elsevier Health Sciences, 195-204.

Mnif, I., Hammami, I., Triki, M. A., Azabou, M. C., EllouzeChaabouni, S., \& Ghribi, D. (2015). Antifungal efficiency of a lipopeptide biosurfactant derived from Bacillus subtilis $S P B 1$ versus the phytopathogenic fungus, Fusarium solani. Environmental Science and Pollution Research, 22, 1813718147. DOI: 10.1007/s11356-015-5005-6.

Moore, T., Globa, L., Barbaree, J., Vodyanoy, V., \& Sorokulova, I. (2013). Antagonistic activity of Bacillus bacteria against foodborne pathogens. J. Prob. Health, 1(3), 110. DOI: $10.4172 / 2329-8901.1000110$. 
Nevezhina, A. V. (2021). Carbapenemases as factors of resistance to antibacterial drugs. Acta Biomedica Scientifica (East Siberian Biomedical Journal), 65, 95. DOI: 10.29413/ABS.2020-5.6.11.

Olaitan, P. B., Adeleke, O. E., \& Iyabo, O. O. (2007). Honey: a reservoir for microorganisms and an inhibitory agent for microbes. African health sciences, 7(3), 159-165. DOI: 10.5555/afhs.2007.7.3.159.

Paytuví-Gallart, A., Sanseverino, W., \& Winger, A. M. (2020). Daily intake of probiotic strain Bacillus subtilis DE111 supports a healthy microbiome in children attending day-care. Beneficial Microbes, 11(7), 611-620. DOI: 10.3920/BM2020.0022.

Polishchuk, A. G., Yakubovich, E. I., \& Polukhina, O. V. (2017). Carbapenemase-producing gram-negative bacteria in a specialized hospital of St. Petersburg Russian Scientific Center for Radiology and Surgical Technologies. Clinical Microbiology and Antimicrobial Chemotherapy, 19(3), 235-242. DOI: 10.15789/2220-7619-2017-2-181-192.

Rodrigues, M. X., Yang, Y., de Souza Meira Jr, E. B., do Carmo Silva, J., \& Bicalho, R. C. (2020). Development and evaluation of a new recombinant protein vaccine (YidR) against Klebsiella pneumoniae infection. Vaccine, 38(29), 4640-4648. DOI: $10.1016 /$ j.vaccine.2020.03.057.

Rozhenkov, A. S., Delaev, U. A., \& Baitaev, M. O. (2017). Structure and functioning of the honey of the honey bee. In: Modern problems of beekeeping, Grozny, 192-195.

Rusaleyev, V. S., Pruntova, O. V., \& Vasilyev, D. A. (2019). Cultural morphological and biochemical characteristics of Bacillus Subtilis strains. Veterinariya segodnya, 1(28), 58-62. DOI: 10.29326/2304-196X-2019-1-28-58-62.

Silva, M. S., Rabadzhiev, Y., Eller, M. R., Iliev, I., Ivanova, I., \& Santana, W. C. (2017). Microorganisms in honey. Honey analysis, 500. DOI: $10.557772 / 67262$.

Stein, T. (2005). Bacillus subtilis antibiotics: structures, syntheses and specific functions. Mol. Microbiol, 56, 845-857. DOI: 10.1088/1742-6596/1751/1/012096.

Sumi, C. D., Yang, B. W., Yeo, I. C., \& Hahm, Y. T. (2015). Antimicrobial peptides of the genus Bacillus: a new era for antibiotics. Canadian Journal of microbiology, 61(2), 93-103. DOI: $10.1139 / \mathrm{cjm}-2014-0613$.
Vachvanichsanong, P., McNeil, E. B., \& Dissaneewate, P. (2021). Extended-spectrum beta-lactamase Escherichia coli and Klebsiella pneumoniae urinary tract infections. Epidemiology \& Infection, 149. DOI: 10.1017/S0950268820003015.

Vignesh, R., Ravindran, J., \& Swathirajan, C. R. (2016). Biocontrol and other beneficial activities of Bacillus subtilis strains isolated from cow dung, soil compost and soil rhizosphere microflora. EC Bacteriol. and Virol. Res, 1(1), 31-35.

Wang, Y., Zhang, H., Zhang, L., Liu, W., Zhang, Y., Zhang, X., \& Sun, T. (2010). In vitro assessment of probiotic properties of Bacillus isolated from naturally fermented congee from Inner Mongolia of China. World Journal of Microbiology and Biotechnology, 26, 1369-1377. DOI: 10.1007/s11274-010-0309-7.

Witazora, Y., Suhartati, T., Satria, H., \& Hadi, S. (2021). Production, purification and characterization of the $\alpha$-amylase from local bacteria isolate Bacillus subtilis ITBCCB148. In Journal of Physics: Conference Series, 1751(1), 012096. DOI: 10.1088/1742-6596/1751/1/012096.

Zahoor, A., Lindner, S. N., \& Wendisch, V. F. (2012). Metabolic engineering of Corynebacterium glutamicum aimed at alternative carbon sources and new products. Computational and structural biotechnology journal, 3(4), e201210004. DOI: $10.5936 / \mathrm{csbj} .201210004$.

Zasada, A. A. (2020). Detection and identification of Bacillus anthracis: From conventional to molecular microbiology methods. Microorganisms, 8(1), 125. DOI: 10.3390/microorganisms8010125.

Zhou, S., Song, D., Zhou, X., Mao, X., Zhou, X., Wang, S., Weia, J., Huanga, Y., Wange. W., Xiao, S. M., \& Qin, Q. (2019). Characterization of Bacillus subtilis from gastrointestinal tract of hybrid Hulong grouper (Epinephelus fuscoguttatus $\times$ E. lanceolatus) and its effects as probiotic additives. Fish \& shellfish immunology, 84, 1115-1124. DOI: 10.1016/j.fsi.2018.10.058.

Zulkhairi Amin, F. A., Sabri, S., Ismail, M., Chan, K. W., Ismail, N., Mohd Esa, N., Azmi M., \& Zawawi, N. (2020). Probiotic properties of Bacillus strains isolated from stingless bee (Heterotrigona itama) honey collected across Malaysia. International journal of environmental research and public health, 17(1), 278. DOI: 10.3390/ijerph17010278. 